\title{
CICLOS DE COMÉRCIO EXTERIOR: UM ESTUDO COMPARATIVO ENTRE BRASIL E ESPÍRITO SANTO(*) ${ }^{(* *)}$
}

\author{
Matheus Albergaria de Magalhães ${ }^{a}$ \\ Victor Nunes Toscano ${ }^{b}$
}

\begin{abstract}
RESUMO: O presente trabalho tem como objetivo documentar as principais regularidades empíricas ("fatos estilizados") relacionadas ao comércio exterior do Brasil e do estado do Espírito Santo em frequências cíclicas. Para tanto, constrói-se uma base de dados referentes a variáveis dos setores externos estadual e nacional ao longo de um período de dez anos (2002-2011), atentando para seu desempenho de curto prazo, com ênfase na volatilidade e persistência das flutuações observadas. Os resultados obtidos permitem concluir que, além das variáveis de comércio exterior serem mais voláteis que as medidas de nível de atividade, eles apresentam um padrão procíclico e defasado. Adicionalmente, constata-se que o saldo da balança comercial apresenta um padrão marcadamente contracíclico e que as flutuações das variáveis de comércio exterior são, em média, mais voláteis no caso espírito-santense do que no caso brasileiro. Por outro lado, não há evidências robustas voltadas para a possível ocorrência de uma "curva-S" relacionando saldo da balança comercial e termos de troca. Estes resultados são importantes por constituírem uma primeira tentativa de documentação de regularidades do comércio exterior estadual e nacional em horizontes de tempo correspondentes a ciclos de negócios.
\end{abstract}

PALAVRAS-CHAVE: Ciclos de negócios; comércio internacional; Espírito Santo.

CLASSIFICAÇÃO JEL: E32; F10; F41.

Artigo recebido em 24/04/2012 e aprovado em 18/07/2013.

** O presente trabalho corresponde a uma versão substancialmente revisada de Magalhães e Toscano (2012c). Os autores agradecem os comentários e sugestões de Fábio Gomes e de alguns participantes do III Encontro de Economia do Espírito Santo (III EEES), que muito contribuíram para aprimorar a versão anterior. Um agradecimento especial a um parecerista anônimo, à Carolina Dias e ao Editor, David Kupfer, pela paciência e auxílio durante o processo de revisão da versão original do trabalho. As opiniões aqui contidas não refletem a visão do IJSN ou de algum de seus membros. Finalmente, vale a ressalva usual de que os erros e idiossincrasias remanescentes devem-se única e exclusivamente aos autores.

a Mestre em Economia pela Universidade de São Paulo (USP) e pela Ohio StateUniversity, especialista em Pesquisas Governamentais do Instituto Jones dos Santos Neves (IJSN). Contato: matheus@ijsn.es.gov.br.

$b$ Mestre em Economia pela Universidade Federal do Espírito Santo (UFES) e técnico de Planejamento do Instituto Jones dos Santos Neves (IJSN). Contato: victor.toscano@ijsn.es.gov.br. 


\title{
INTERNATIONAL BUSINESS CYCLES: A COMPARATIVE STUDY BETWEEN BRAZIL AND ESPÍRITO SANTO
}

\begin{abstract}
This work aims to document the main empirical regularities (stylized facts) over business-cycle frequencies related to Brazil and the state of Espírito Santo's international trade. In doing so, we build an extensive dataset related to exports and imports' values covering a 10-year horizon (2002-2011). Results obtained demonstrate that international trade variables are more volatile than output measures and present procyclical and lagging patterns over the business cycle. Additionally, trade balance measures display a countercyclical pattern, with state-level fluctuations being more volatile than country's fluctuations. On the other hands, there is no robust evidence related to an "S-curve" pattern, relating trade balance and the terms of trade. These results are important for providing a first set of moments related to the state and country's international trade over cyclical frequencies.
\end{abstract}

KEYWORDS: Business cycles; international trade; Espírito Santo. 


\section{INTRODUÇÃO}

O comércio exterior apresenta consideráveis flutuações no curto prazo. Por exemplo, ao longo da crise de 2007-2008, foi reportada uma queda consideravelmente superior nos volumes transacionados no contexto internacional em comparação à queda reportada para o nível de atividade global. Apenas para se ter uma ideia das magnitudes relativas, vale citar que, no caso dos Estados Unidos, foram reportadas quedas percentuais em torno de $20 \%$ nas exportações e importações, ao passo que o nível de atividade registrou uma queda significativamente menor, em torno de $4 \%$ (Levchenko, Lewis e Tesar 2010) ${ }^{1}$. À primeira vista, estes fatos apontam para a existência de significativas diferenças, em termos de volatilidade, relacionadas as variáveis de comércio exterior.

Ao mesmo tempo, o comércio exterior desempenha importante papel na determinação do nível de atividade de algumas economias estaduais, conforme é o caso do Espírito Santo. O elevado coeficiente de abertura da economia local (estimado em torno de 50\%), associado a um alto grau de concentração da pauta de exportações em bens básicos e intermediários (commodities, em sua maioria) faz com que, em média, acontecimentos ocorridos no cenário externo tenham maior impacto sobre o nível de atividade local em comparação a outros estados brasileiros².

Por conta disto, o objetivo do presente artigo é apresentar uma caracterização inicial das principais regularidades empíricas ("fatos estilizados") relacionadas ao comportamento cíclico de variáveis de comércio exterior nacional e estadual no curto prazo. As vantagens de um empreendimento nestes moldes são basicamente duas. Primeiro, apesar de terem sido reportados esforços de pesquisa anteriores, relacionados à documentação de fatos estilizados de ciclos de negócios, a ampla maioria desses esforços possui abrangência nacional, com pouca ênfase sobre o contexto regional ${ }^{3}$.

Segundo, não se tem notícia até o presente momento, de esforços voltados para a caracterização de fatos relacionados ao comércio exterior nacional e/ou estadual em

\footnotetext{
Exemplos de análises dos efeitos adversos da crise de 2007-2008, com ênfase nos contextos norte-americano e internacional, podem ser encontrados em Blanchard (2009), Brunermeier (2009), Levchenko, Lewis e Tesar (2010) e Alessandria, Kaboski e Midrigan (2011). No caso de análises aplicadas ao contexto nacional, ver De Paula (2008), Levy (2008), Bresser-Pereira (2009), Lopes (2009) e Ribeiro (2009).

2 Para caracterizações empíricas do comércio exterior do estado do Espírito Santo, ver Pereira e Maciel (2010), Prates (2010) e Magalhães e Toscano (2010, 2012a, 2012b, 2012d). No caso do comércio exterior nacional, ver, a título de exemplo, Bonelli (2006), Kume, Piani e Miranda (2008), e Hidalgo e Feistel (2013).

3 Estudos que registram fatos estilizados dos ciclos de negócios em âmbito nacional correspondem a Kanczuk e Faria (2000), Ferreira e Val (2001), Ellery, Gomes e Sachsida (2002), e Ellery e Gomes (2005). Por sua vez, Cunha e Moreira (2006) e Magalhães e Ribeiro (2011) correspondem a estudos focados no contexto regional.
} 
frequências cíclicas, nos moldes propostos por autores como Backus, Kehoe e Kydland (1992), por exemplo. Dada a importância do comércio exterior para o estado do Espírito Santo, a economia local pode vir a representar um interessante laboratório relacionado à dinâmica de curto prazo de uma pequena economia aberta. Em última instância, os resultados aqui reportados podem constituir um conjunto de momentos útil à calibração e simulação de modelos teóricos destinados a explicar as realidades estadual e nacional.

Além desta introdução, o trabalho contém cinco seções adicionais. A segunda seção apresenta uma revisão de parte da literatura relacionada ao tema de ciclos de negócios no contexto internacional, enquanto que a terceira seção contém uma breve caracterização da estrutura econômica do estado do Espírito Santo. A quarta seção descreve a base de dados empregada na análise. A quinta seção reporta os principais resultados obtidos. Finalmente, a sexta seção apresenta as conclusões e aponta possíveis temas de pesquisa futura.

\section{LITERATURA RELACIONADA}

Embora em voga no início do século XX, estudos relacionados a ciclos de negócios perderam importância relativa ao longo do tempo, tendo retornado em maior frequência no final do século, a partir das décadas de 1980 e 19904. Em um primeiro momento, a maior parte desses estudos buscou documentar as principais regularidades empíricas (também denominadas "fatos estilizados") relacionadas às flutuações cíclicas, tendo como base de análise o caso de uma economia fechada (por exemplo, Kydland e Prescott, 1990).

Com o passar do tempo, surgiram estudos focados na importância do setor externo e as consequências de sua inclusão na análise dos ciclos. Em particular, Mendoza (1991) correspondeu a um esforço pioneiro neste sentido. No caso, analisando a economia canadense, o autor construiu um modelo de equilíbrio geral dinâmico que considera a importância de choques de produtividade sobre o desempenho de uma pequena economia aberta. Ao longo do estudo, Mendoza atentou para duas importantes regularidades empíricas, recorrentes no cenário internacional: primeiro, o fato de que as variáveis poupança e investimento são altamente correlacionadas em frequências cíclicas, mesmo no caso de ocorrência de um alto grau de mobilidade de capitais; segundo, o fato das variáveis balanço em transações correntes e saldo da balança comercial apresentarem

\footnotetext{
4 Para exemplos de análises da evolução histórica de teorias relacionadas com ciclos de negócios, ver Zarnowitz (1985), Woodford (1999) e Blanchard (2000). Uma resenha em português está contida em Magalhães (2000).
} 
um padrão contracíclico. Os resultados obtidos chamam atenção para a importância de choques originados a partir dos termos de troca em países em desenvolvimento que apresentam alta dependência de exportações de bens primários e intermediários (por exemplo, commodities).

Por sua vez, analisando uma amostra contendo dados relacionados a dez países desenvolvidos, ao longo do período 1850-1986 (dados anuais), Backus e Kehoe (1992) documentaram alguns dos principais fatos estilizados relacionados aos ciclos de negócios. Em termos gerais, os resultados obtidos por esses autores demonstram que, apesar de existirem consideráveis diferenças entre países e períodos de tempo, em termos de volatilidade e grau de comovimento dos ciclos reportados, pode-se verificar, relativamente, a ocorrência de um padrão no caso das variáveis macroeconômicas analisadas. Em última instância, os resultados obtidos estão em consonância com a análise desenvolvida por Lucas (1977), onde o autor defende a ideia de que, dada a ocorrência de regularidades empíricas relacionadas a ciclos de negócios, passa a ser possível a formulação e teste de teorias genéricas relacionadas a este fenômeno ${ }^{5}$.

Basu e Taylor (1999) estenderam a análise original de Backus e Kehoe (1992), ressaltando a importância de aspectos teóricos e empíricos relacionados ao estudo dos ciclos de negócios em nível internacional. Além de verificarem a ocorrência de diversos fatos estilizados, os autores ressaltam a importância de fatores inerentes a países específicos na explicação dos ciclos, com ênfase no padrão empírico de taxas de câmbio e salários reais. Os resultados obtidos chamam atenção para a importância de aspectos históricos e institucionais na explicação de ciclos de negócios em escala internacional.

Backus, Kehoe e Kydland (1992) procuraram responder se um modelo de ciclos de negócios envolvendo dois países é capaz de replicar as principais regularidades empíricas relacionadas ao setor externo de uma economia real. Para tanto, reportaram um conjunto de momentos relacionado a variáveis macroeconômicas específicas, com ênfase nas discrepâncias existentes entre fatos estilizados e modelos teóricos. A Tabela 1 resume alguns dos principais resultados obtidos para a economia norte-americana ao longo do período 1954:01-1985:03 (dados trimestrais):

\footnotetext{
Para maiores detalhes a este respeito, ver Lucas $(1977,1980)$. As recomendações metodológicas de Lucas acabaram dando origem à agenda de pesquisa relacionada aos modelos Real-Business-Cycle (RBC). Exemplos de resenhas relacionadas ao tema correspondem a McCallum (1989), Plosser (1989), Stadler (1994), Cooley e Prescott (1995) e King e Rebelo (2000). Análises de aspectos metodológicos desta agenda podem ser encontradas em Danthine e Donaldson (1993), Chari (1998) e Magalhães (2005).
} 
Tabela 1 - Resultados de Backus, Kehoe e Kydland (1992) para os Estados Unidos (1954:01-1985:03)

\begin{tabular}{l|c|c}
\hline \multicolumn{1}{c|}{ Variável } & Desvio-padrão & Correlação com Produto \\
\hline Produto & 1,00 & 1,00 \\
\hline Consumo & 0,49 & 0,76 \\
\hline Investimento & 3,15 & 0,90 \\
\hline Horas trabalhadas & 0,86 & 0,86 \\
\hline Estoque de capital & 0,37 & 0,01 \\
\hline Saldo Comercial/Produto & - & $-0,28$ \\
\hline
\end{tabular}

Notas: Dados trimestrais. (a) Os dados utilizados para calcular as estatísticas acima possuem periodicidade trimestral, englobando o período 1954:01-1985:03. Em um primeiro momento, os dados originais foram convertidos para a escala logarítmica natural, exceto pela razão "Saldo Comercial/Produto". Posteriormente, os componentes cíclicos das séries foram obtidos a partir do filtro de Hodrick-Prescott (Hodrick e Prescott, 1997). (b) A segunda coluna da tabela reporta valores dos desvios-padrão calculados para as variáveis consideradas como proporção do desvio-padrão do produto.(c) A terceira coluna da tabela reporta valores dos coeficientes de correlação cruzada calculados entre cada variável e a medida de produto real. Fonte: Backus, Kehoe e Kydland (1992, p. 750).

Os resultados reportados permitem inferir alguns fatos interessantes relacionados ao desempenho do setor externo norte-americano ao longo do período considerado. Primeiro, nota-se que o consumo apresenta uma menor volatilidade que o produto, equivalente a quase $50 \%$ do valor reportado para a primeira variável (desvio-padrão relativo de 0,49 ), exibindo um padrão procíclico (coeficiente de correlação cruzada de 0,76). Segundo, o investimento revela-se a variável macroeconômica de maior volatilidade na Tabela 1, equivalente a mais de três vezes a volatilidade do produto (desvio-padrão de 3,15), também apresentando o maior valor reportado para o coeficiente de correlação cruzada $(0,90)$, o que permite caracterizar esta variável como exibindo um padrão procíclico. A variável representando o nível de emprego da economia (horas trabalhadas), além de apresentar alto grau de correlação com o produto, também apresenta uma volatilidade semelhante, com ambos os coeficientes exibindo a mesma magnitude, no caso $(0,86)$. Por sua vez, o estoque de capital, além de apresentar uma volatilidade significativamente inferior àquela reportada para o produto (desvio-padrão relativo de 0,37 ), também apresenta um baixo grau de associação linear (coeficiente de correlação de 0,01 ), resultado que aponta para um padrão de relativa estabilidade desta variável no curto prazo, condizente com outros estudos do gênero ${ }^{6}$.

Um fato que chama atenção na tabela é o resultado referente ao comportamento da razão "saldo comercial/produto", cujo coeficiente de correlação linear com o produto

6 Para exemplos de estudos que chegam a resultados semelhantes àqueles reportados na Tabela 1 , ver, a título de exemplo, Kydland e Prescott (1990), Backus e Kehoe (1992), Cooley e Prescott (1995), e Stock e Watson (2000). 
apresenta valor negativo (-0,28), denotando um padrão contracíclico. Adicionalmente, os autores reportam que, ao considerarem outros países na análise, notam que as correlações entre os respectivos níveis de produto tendem a ser mais altas que aquelas referentes aos níveis de consumo, embora este padrão não ocorra no caso de modelos teóricos destinados a replicar um comportamento nestes moldes. Em relação a esta última discrepância, os autores destacam o fato do produto de distintos países ser mais correlacionado que o consumo, embora um padrão contrário ocorra no caso dos modelos teóricos ${ }^{7}$. Finalmente, reportam que as variáveis investimento e balança comercial são consideravelmente mais voláteis em economias artificiais quando da comparação com a economia real. Em termos gerais, os autores concluem que a inclusão do setor externo tende a afetar significativamente a dinâmica de análise das flutuações cíclicas, com uma menor aderência dos modelos teóricos aos dados em comparação a modelos de economia fechada, por exemplo ${ }^{8}$.

Em outra ocasião, Backus, Kehoe e Kydland (1994) focam sua análise no comportamento cíclico de um maior número de variáveis especificamente relacionadas ao comércio exterior. Em particular, os autores analisam o comportamento do índice de termos de troca e da balança comercial de 11 países desenvolvidos. Um importante resultado reportado pelos autores diz respeito ao comportamento empírico da balança comercial dos países da amostra: esta variável tende a exibir, em média, um padrão contracíclico, sendo negativamente correlacionada com movimentos correntes e futuros do índice de termos de troca, embora seja positivamente correlacionada com movimentos passados. Um padrão assimétrico nestes moldes é denominado de “curva-S" pelos autores, em alusão ao aspecto gráfico das correlações cruzadas estimadas para as variáveis supracitadas". Os autores também reportam a ocorrência da "anomalia consumo/produto"

\footnotetext{
Especificamente, os autores denominam essa discrepância de "anomalia consumo/produto", propondo que novos desenvolvimentos teóricos busquem resolvê-la (Backus, Kehoe e Kydland, 1992, p. 772).

8 Em uma tentativa de verificar a robustez das principais regularidades empíricas relacionadas com ciclos de negócios em nível internacional, Ambler, Cardia e Zimmermann (2004) utilizam dados trimestrais referentes a 20 países. Empregando o Método Generalizado de Momentos (MGM), os autores revisitam o estudo de Backus, Kehoe e Kydland (1992) a partir de uma maior amostra, com ênfase na estimação de correlações cruzadas entre variáveis macroeconômicas de interesse. Os resultados obtidos a partir deste exercício empírico demonstram que, em média, as correlações estimadas são positivas em sua maioria e apresentam magnitudes razoavelmente similares. Em particular, os autores reportam a não ocorrência de coeficientes de correlação estatisticamente significativos relacionados com co-movimentos entre distintos países.

9 Adicionalmente, os autores notam que esta denominação faz referência à chamada "curva-J", equivalente ao resultado empírico onde desvalorizações tendem a gerar movimentos desfavoráveis sobre os termos de troca, que estariam inicialmente associados a declínios na balança comercial, sendo posteriormente revertidos ao longo de um período de tempo entre dois e oito trimestres (Backus, Kehoe e Kydland, 1994, p.87-89).
} 
para o conjunto de países utilizado na análise. Em termos gerais, chamam atenção para a importância de fatores como a persistência de choques de produtividade e a dinâmica de formação do estoque de capital como potenciais explicações para os padrões empíricos reportados.

Engel e Wang (2011) apresentam um interessante estudo focado no comportamento cíclico de exportações e importações. Os autores ressaltam que, em termos gerais, o comportamento individual de exportações e importações tem sido relativamente pouco analisado na literatura especializada em temas macroeconômicos. A partir de uma análise englobando uma amostra de 25 países industrializados da Organização para Cooperação e Desenvolvimento Econômico (OCDE), os autores reportam três fatos estilizados: (i) a volatilidade de exportações e importações tende a apresentar, em média, magnitudes cerca de duas ou três vezes superiores à volatilidade do produto; (ii) exportações e importações exibem um padrão procíclico, sendo positivamente correlacionadas; (iii) há uma relação empírica negativa entre saldo comercial e produto, nos moldes originalmente reportados por Mendoza (1991) e Backus, Kehoe e Kydland (1992). Adicionalmente, os autores apresentam evidências empíricas demonstrando que transações envolvendo bens duráveis respondem pela ampla maioria (cerca de 70\%) dos volumes exportados e importados entre países da OCDE. Os resultados reportados são interessantes não apenas por ressaltarem a importância de bens duráveis para o comércio internacional, mas principalmente por chamarem atenção para a necessidade de um maior volume de pesquisa relacionado ao comportamento individual de exportações e importações no curto prazo ${ }^{10}$.

Levchenko, Lewis e Tesar (2010) analisam potenciais explicações relacionadas ao colapso do comércio internacional ocorrido ao longo da crise de 2008-2009. Para tanto, utilizam informações desagregadas de comércio exterior em frequências cíclicas (dados mensais e trimestrais) para os Estados Unidos e apresentam exercícios empíricos e resultados econométricos relacionados ao poder explicativo de distintas teorias de comércio internacional. A principal conclusão obtida pelos autores demonstra que o colapso do comércio internacional ocorrido durante a crise apresentou um caráter excepcional em dois sentidos: primeiro, a queda verificada no nível de atividade da economia norte-americana foi significativamente superior em comparação àquela observada em outros períodos recessivos; segundo, esta queda também foi superior às previsões advindas de modelos teóricos de ciclos de negócios em nível internacional. Em termos de teorias alternativas, os resultados empíricos reportados favorecem explicações base-

\footnotetext{
${ }^{10}$ Leibovici e Waugh (2011) analisam o comportamento de importações norte-americanas em frequências cíclicas, com ênfase na relação entre volumes importados, nível de atividade e medidas de preços.
} 
adas em padrões de especialização vertical e efeitos de composição. Por outro lado, os autores não encontram suporte para explicações baseadas na redução do crédito como principal canal para a contração observada no nível de atividade.

Gopinath, Itshoki e Neiman (2011) analisam o comportamento de preços de exportações e importações durante a crise de 2008-2009 a partir da utilização de uma amostra baseada em microdados do Bureau of Labor Statistics (BLS). Em particular, focam sua análise no período compreendido entre os meses de setembro de 2008 e março de 2009, correspondente ao colapso ocorrido no comércio internacional. Os autores reportam que, ao longo do período analisado, ocorreram significativas diferenças entre preços de bens diferenciados e não diferenciados, com os primeiros exibindo um padrão de estabilidade, ao passo que os últimos registraram um padrão de queda. Adicionalmente, relatam que, apesar de terem ocorrido significativas quedas nos valores transacionados internacionalmente, não ocorreram, em média, mudanças nos preços cobrados da maioria dos produtos analisados, com a exceção ficando por conta de bens não duráveis e intermediários, tradicionalmente relacionados ao segmento de commodities. Finalmente, reportam que, com o início da crise, foram registradas consideráveis mudanças na frequência e magnitude dos ajustes de preços realizados. Os autores ainda chamam atenção para o fato de que movimentos agregados nos índices de preços analisados tendem, em média, a mascarar significativas disparidades entre preços individuais de bens diferenciados e não diferenciados ${ }^{11}$.

As referências supracitadas, além de enfatizarem a importância do setor externo para a compreensão das flutuações econômicas de curto prazo, constituirão base para a análise empírica conduzida a seguir.

\section{CARACTERIZAÇÃO ECONÔMICA DO ESTADO DO ESPÍRITO SANTO}

Esta seção apresenta uma breve caracterização da economia do estado do Espírito Santo como forma de motivar melhor o tema, assim como descrever algumas das características peculiares da estrutura produtiva local.

A Tabela 2 apresenta valores referentes ao Produto Interno Bruto (PIB) a preços correntes (em milhões de reais) do Brasil (segunda coluna) e do Espírito Santo (terceira coluna). A título de comparação, a quarta coluna apresenta valores correspondentes à razão entre os dados das colunas anteriores. O objetivo principal desta operação é captar a participação relativa da economia estadual na economia nacional.

\footnotetext{
11 Para análises relacionadas com o comportamento dos preços de commodities e seus impactos sobre as economias nacional e estadual, ver, por exemplo, Prates (2007), Prates e Marçal (2008) e Magalhães (2011).
} 
Tabela 2 - PIB a preços correntes, Brasil e Espírito Santo (2002-2008)

\begin{tabular}{c|c|c|c}
\hline Ano & Brasil (1) & Espírito Santo (2) & Participação (\%) ES-BR (2)/(1) \\
\hline 2002 & 1.477 .822 & 26.756 & 1,81 \\
\hline 2003 & 1.699 .948 & 31.064 & 1,83 \\
\hline 2004 & 1.941 .498 & 40.217 & 2,07 \\
\hline 2005 & 2.147 .239 & 47.223 & 2,20 \\
\hline 2006 & 2.369 .484 & 52.778 & 2,23 \\
\hline 2007 & 2.661 .345 & 60.340 & 2,27 \\
\hline 2008 & 3.031 .864 & 69.870 & 2,30 \\
\hline
\end{tabular}

Nota: PIB a preços correntes (R\$1.000.000) e dados anuais.

Fonte: Elaboração própria com base em dados do Instituto Brasileiro de Geografia e Estatística (IBGE).

Os resultados apontam para um cenário no qual, apesar de pequena, a participação do Espírito Santo no PIB nacional exibiu um padrão crescente ao longo do período 20022008, tendo aumentado de 1,8\% no ano de 2002 para 2,3\%, em 2008. Ao longo deste período, as participações média e mediana da economia estadual ficaram em 2,1\% e $2,2 \%$, respectivamente, o que confirma a representatividade da participação em questão.

A Tabela 3, por sua vez, apresenta dados referentes ao PIB per capita das Unidades da Federação (UF), com ênfase nas dez primeiras colocadas em um ranking decrescente de valores. A intenção básica, neste caso, é ressaltar a evolução do nível de bem-estar (medido via PIB per capita) no estado do Espírito Santo ao longo do período 2002-2008.

Tabela 3 - Ranking do PIB per capita nas UF (2002-2008)

\begin{tabular}{|c|c|c|c|c|c|c|c|}
\hline Posição & 2002 & 2003 & 2004 & 2005 & 2006 & 2007 & 2008 \\
\hline 1 & $\begin{array}{l}\text { Distrito } \\
\text { Federal }\end{array}$ & $\begin{array}{l}\text { Distrito } \\
\text { Federal }\end{array}$ & $\begin{array}{l}\text { Distrito } \\
\text { Federal }\end{array}$ & $\begin{array}{l}\text { Distrito } \\
\text { Federal }\end{array}$ & $\begin{array}{l}\text { Distrito } \\
\text { Federal }\end{array}$ & $\begin{array}{l}\text { Distrito } \\
\text { Federal }\end{array}$ & $\begin{array}{l}\text { Distrito } \\
\text { Federal }\end{array}$ \\
\hline 2 & São Paulo & São Paulo & São Paulo & São Paulo & São Paulo & São Paulo & São Paulo \\
\hline 3 & $\begin{array}{l}\text { Rio de } \\
\text { Janeiro }\end{array}$ & $\begin{array}{l}\text { Rio de } \\
\text { Janeiro }\end{array}$ & $\begin{array}{l}\text { Rio de } \\
\text { Janeiro }\end{array}$ & $\begin{array}{l}\text { Rio de } \\
\text { Janeiro }\end{array}$ & $\begin{array}{l}\text { Rio de } \\
\text { Janeiro }\end{array}$ & $\begin{array}{l}\text { Rio de } \\
\text { Janeiro }\end{array}$ & $\begin{array}{l}\text { Rio de } \\
\text { Janeiro }\end{array}$ \\
\hline 4 & $\begin{array}{c}\text { Rio Grande } \\
\text { do Sul }\end{array}$ & $\begin{array}{c}\text { Santa } \\
\text { Catarina }\end{array}$ & Mato Grosso & $\begin{array}{c}\text { Santa } \\
\text { Catarina }\end{array}$ & $\begin{array}{c}\text { Santa } \\
\text { Catarina }\end{array}$ & $\begin{array}{c}\text { Espírito } \\
\text { Santo }\end{array}$ & $\begin{array}{c}\text { Santa } \\
\text { Catarina }\end{array}$ \\
\hline 5 & $\begin{array}{c}\text { Santa } \\
\text { Catarina }\end{array}$ & $\begin{array}{c}\text { Rio Grande } \\
\text { do Sul }\end{array}$ & $\begin{array}{c}\text { Santa } \\
\text { Catarina }\end{array}$ & $\begin{array}{l}\text { Espírito } \\
\text { Santo }\end{array}$ & $\begin{array}{l}\text { Espírito } \\
\text { Santo }\end{array}$ & $\begin{array}{c}\text { Santa } \\
\text { Catarina }\end{array}$ & $\begin{array}{c}\text { Espírito } \\
\text { Santo }\end{array}$ \\
\hline 6 & Paraná & Paraná & $\begin{array}{c}\text { Rio Grande } \\
\text { do Sul }\end{array}$ & Mato Grosso & $\begin{array}{c}\text { Rio Grande } \\
\text { do Sul }\end{array}$ & $\begin{array}{c}\text { Rio Grande } \\
\text { do Sul }\end{array}$ & $\begin{array}{c}\text { Rio Grande } \\
\text { do Sul }\end{array}$ \\
\hline 7 & $\begin{array}{l}\text { Espírito } \\
\text { Santo }\end{array}$ & Mato Grosso & Paraná & $\begin{array}{c}\text { Rio Grande } \\
\text { do Sul }\end{array}$ & Paraná & Paraná & Mato Grosso \\
\hline 8 & Mato Grosso & $\begin{array}{l}\text { Espírito } \\
\text { Santo }\end{array}$ & $\begin{array}{l}\text { Espírito } \\
\text { Santo }\end{array}$ & Paraná & Mato Grosso & Mato Grosso & Paraná \\
\hline 9 & Amazonas & $\begin{array}{c}\text { Mato Grosso } \\
\text { do Sul }\end{array}$ & Amazonas & Amazonas & Amazonas & Amazonas & Minas Gerais \\
\hline 10 & Goiás & Amazonas & $\begin{array}{c}\text { Mato Grosso } \\
\text { do Sul }\end{array}$ & Minas Gerais & Minas Gerais & Minas Gerais & $\begin{array}{c}\text { Mato Grosso } \\
\text { do Sul }\end{array}$ \\
\hline
\end{tabular}

Nota: dados anuais.

Fonte: Elaboração própria com base em dados das Contas Regionais do IBGE. 
De acordo com os resultados reportados na Tabela 3, pode-se notar uma clara evolução da colocação do estado no ranking das UF ao longo do período analisado. Em particular, nota-se que o Espírito Santo saiu da oitava colocação no ano de 2003 para a quinta colocação em 2005, chegando, inclusive, a alcançar a quarta colocação no ano de 2007. Apesar das limitações inerentes a esta medida de bem-estar, os resultados supracitados apontam para um padrão de evolução da economia estadual no contexto nacional.

Por outro lado, em termos de comércio exterior, vale notar que o Espírito Santo pode ser caracterizado como um dos estados com maior grau de abertura do país. Distintos estudos destinados a calcular o coeficiente de abertura estadual chegaram à mesma conclusão em relação a sua posição ante outras UF, embora possa haver discordância em termos de magnitudes do coeficiente de abertura propriamente dito, provavelmente decorrente de diferenças relacionadas a períodos de análise e/ou metodologia empregados (Souza, 2003; Magalhães e Toscano, 2010; Pereira e Maciel, 2010). Em termos gerais, estimativas referentes a este coeficiente ficam em torno de $50 \%$; ou seja, a cada R \$ 100 produzidos no estado, cerca de metade é destinada a transações com o exterior.

Quanto à pauta de exportações, o Espírito Santo pode ser caracterizado principalmente como um estado exportador de bens básicos e intermediários. A Tabela 4 contém dados que corroboram com esta última afirmação, apresentando os dez principais produtos exportados ao longo do período 1997-2011.

Tabela 4 - Dez principais produtos exportados pelo Espírito Santo (1997/2011)

\begin{tabular}{l|c|c}
\hline \multicolumn{1}{c|}{ Mercadoria NCM } & Valores (US\$ Bilhões) & Participação (\%) \\
\hline 1. Minérios de ferro aglomerados e concentrados & 32,27 & 41 \\
\hline 2. Produtos semimanufaturados de ferro e aço & 11,86 & 15 \\
\hline 3. Pasta química de madeira (Celulose) & 10,20 & 13 \\
\hline 4. Café em grão & 4,39 & 6 \\
\hline 5. Outros granitos trabalhados e suas obras & 3,61 & 5 \\
\hline 6. Produtos semimanufaturados, de outras ligas de aços & 1,89 & 2 \\
\hline 7. Óleos brutos de petróleo & 1,65 & 2 \\
\hline 8. Combustíveis e lubrificantes para embarcações & 1,23 & 2 \\
\hline 9. Outros laminados de ferro e aço & 1,18 & 2 \\
\hline 10. Outros tubos flexíveis de ferro e aço & 1,07 & 1 \\
\hline Total & 69,35 & \\
\hline
\end{tabular}

Nota: dados anuais.

Fonte: Magalhães e Toscano (2012d, p. 88).

De acordo com os resultados contidos na Tabela 4, nota-se que, durante o período analisado, o minério de ferro aparece como o principal produto exportado pelo estado, com uma participação de $41 \%$ na pauta. Em seguida, vêm produtos semimanufaturados de ferro e aço, com uma participação inferior à metade do primeiro colocado no ranking, 
de $15 \%$. A celulose vem em terceiro lugar, com uma participação de $13 \%$. Em quarto e quinto lugares vêm café e outros granitos trabalhados, com participações de $6 \%$ e 5\%, respectivamente. Os demais produtos do ranking apresentam participações razoavelmente semelhantes, em torno de $2 \%$. No total, os dez produtos listados na tabela respondem por quase $90 \%$ dos valores exportados pelo estado. Em termos gerais, estes resultados apontam para um alto grau de concentração da pauta espírito-santense de exportações ${ }^{12}$.

Devido ao alto grau de abertura e à elevada concentração da pauta de exportações, o estado do Espírito Santo apresenta, em geral, maior volatilidade relativa em suas flutuações econômicas em comparação ao Brasil e demais UF. O Gráfico 1 descreve a evolução dos componentes cíclicos das séries históricas de produção industrial do Brasil e Espírito Santo ao longo do período 1991:01-2011:02 (Dados Trimestrais) ${ }^{13}$. Adicionalmente, o gráfico expõe as recessões ocorridas no país ao longo deste período, em consonância com a cronologia proposta por Gomes e Magalhães (2012) para o contexto espírito-santense.

\section{Gráfico 1 - Componentes cíclicos de índices de produção industrial do Brasil e do Espírito Santo (1991:01-2011:02)}

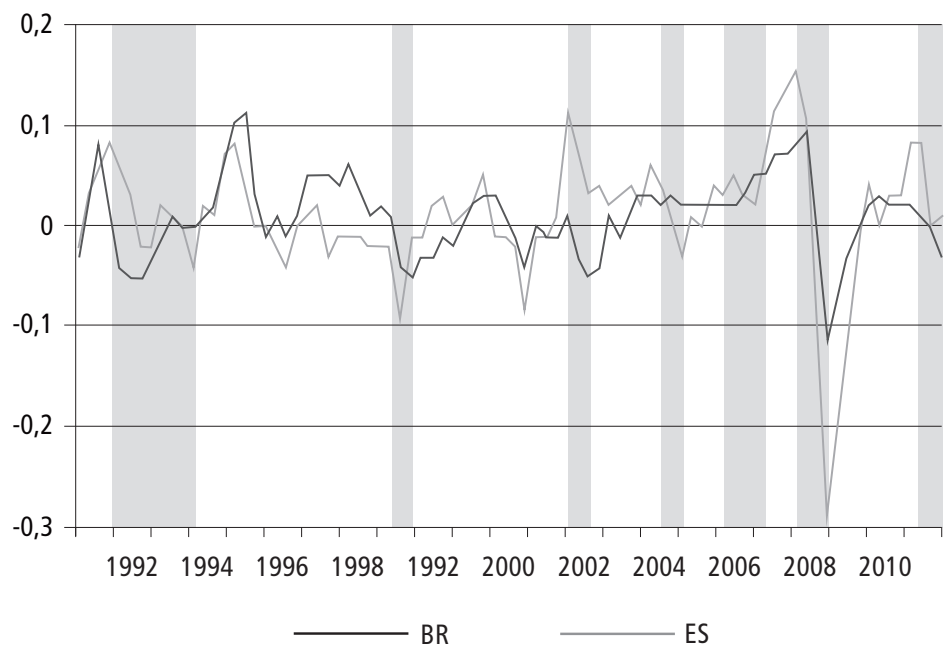

Notas: Dados trimestrais. Os dados utilizados no gráfico possuem periodicidade trimestral, englobando o período 1991:012009:02. Todos os dados estão em escala logarítmica, com seus componentes cíclicos tendo sido obtidos a partir do filtro Hodrick-Prescott, considerando $\lambda=1.600$. Áreas sombreadas correspondem a períodos de recessão ocorridos no Espírito Santo, em consonância com a cronologia desenvolvida por Gomes e Magalhães (2012).

Fonte: Elaboração própria com base em dados da Pesquisa Industrial Mensal de Produção Física (PIM-PF) do IBGE.

12 Análises das pautas de exportação e importação do Espírito Santo podem ser encontradas em Pereira e Maciel (2010), Prates (2010) e Magalhães e Toscano (2012a, 2012d).

${ }^{13}$ No caso de análises relacionadas à maior volatilidade relativa da economia espírito-santense em comparação à economia brasileira, ver Magalhães e Ribeiro (2011), Magalhães e Toscano (2012a) e Gomes e Magalhães (2012). 
O padrão gráfico reportado anteriormente permite inferir dois fatos: primeiro, os ciclos das séries de produção industrial nacional e estadual apresentam um padrão contracionista ao longo da maior parte das recessões ocorridas no país, embora não haja um perfeito padrão de sincronia; segundo, nota-se uma maior volatilidade relativa dos ciclos industriais do estado, em comparação aos ciclos do país, especialmente no caso dos últimos períodos da amostra.

Em suma, os resultados reportados neste item demonstram que a economia do Espírito Santo pode ser caracterizada como uma pequena economia aberta, dado seu alto grau de abertura ao comércio exterior e a concentração de suas exportações em bens básicos e intermediários (commodities), o que, por sua vez, faz com que sofra oscilações relativamente mais voláteis no curto prazo quando da comparação com o Brasil e demais UF. A análise subsequente baseia-se nestes resultados para documentar os principais fatos estilizados relacionados a padrões cíclicos de comércio exterior ao longo do período 2002-2011.

\section{BASE DE DADOS}

Os dados utilizados neste trabalho correspondem a valores de exportações e importações referentes a produtos registrados para Brasil e Espírito Santo ao longo do período compreendido entre os anos de 2002-2011. Basicamente, este período amostral foi escolhido com base na disponibilidade comum de dados de comércio exterior. Conforme dito anteriormente, a frequência temporal adotada na análise subsequente foi trimestral, em consonância com estudos relacionados a ciclos de negócios (por exemplo, Cooley e Prescott, 1995).

Os dados analisados correspondem a fluxos estaduais de exportação e importação cobrindo um período de aproximadamente dez anos e englobando um conjunto superior a 2.000 bens transacionados em cerca de 180 países. Especificamente, foram coletadas informações de produtos exportados e importados para cada ano da amostra ao menor nível de agregação disponível (oito dígitos), em acordo com a Nomenclatura Comum do Mercosul (NCM). A fonte primária dos dados equivale à Secretaria de Comércio Exterior (SECEX), do Ministério do Desenvolvimento, Indústria e Comércio Exterior (MDIC).

As consultas às variáveis de interesse foram feitas a partir do Sistema de Análise de Informações de Comércio Exterior via Internet, denominado Aliceweb. Segundo informações disponíveis neste sistema, a classificação NCM de mercadorias é regida pelas Regras Gerais para Interpretação do Sistema Harmonizado, sendo composta por oito dígitos, onde os seis primeiros são formados a partir do Sistema Harmonizado (capí- 
tulo, posição e subposição) enquanto que os dois últimos (item e subitem) são criados de acordo com a definição estabelecida entre países do Mercosul.

Para mensurar o nível de atividade estadual e nacional, foram utilizados índices de produção industrial (Indústria Geral) da Pesquisa Industrial Mensal de Produção Física (PIM-PF) do IBGE. A partir de informações relacionadas a exportações, importações e nível de atividade, foram construídas variáveis adicionais relacionadas ao comércio exterior, como a corrente de comércio (soma de exportações e importações), o saldo da balança comercial (diferença entre exportações e importações) e os termos de troca (razão entre preços de exportações e importações) ${ }^{14}$.

\section{RESULTADOS}

Nesta seção são reportados os principais resultados do trabalho. O Gráfico 2 contém a evolução dos componentes cíclicos das séries históricas de produção industrial, exportações e importações do Brasil e Espírito Santo, ao longo do período 2002:01-2011:02 (dados trimestrais).

Adicionalmente são expostas nos gráficos as áreas correspondentes a períodos recessivos ocorridos na economia brasileira, em consonância com a cronologia proposta pelo Comitê de Datação dos Ciclos Econômicos (CODACE 2009) do Instituto Brasileiro de Economia da Fundação Getúlio Vargas (IBRE-FGV) (caso nacional), assim como a cronologia proposta por Gomes e Magalhães (2012) (caso estadual).

\footnotetext{
${ }^{14}$ Leitores interessados em obter a base de dados utilizada neste trabalho podem fazê-lo entrando em contato diretamente com os autores.
} 


\section{Gráfico 2 - Componentes cíclicos de exportações, importações e índice de produção industrial, Brasil e Espírito Santo (2002:01-2011:02)}
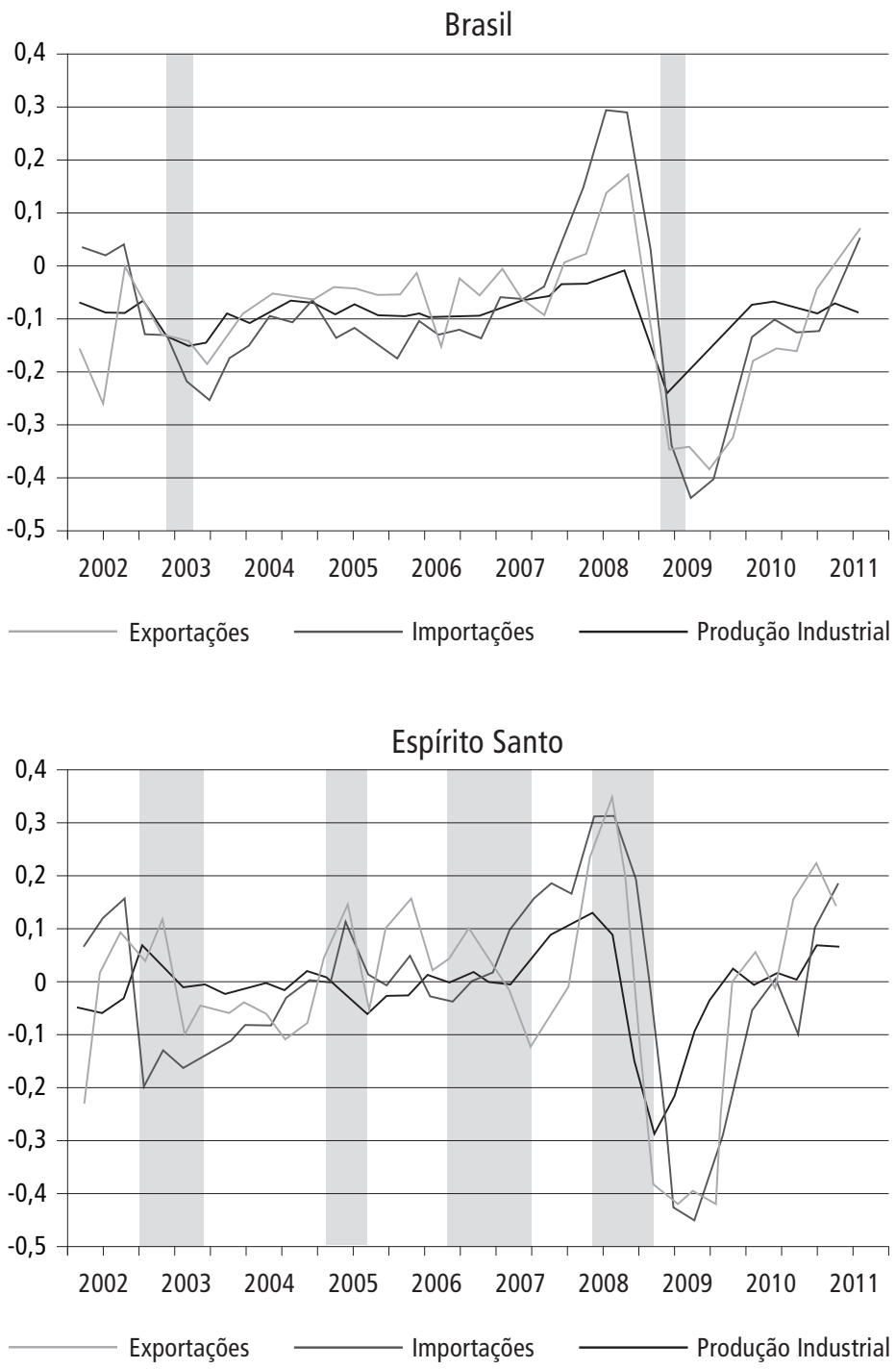

Notas: (a) Os dados utilizados no gráfico possuem periodicidade trimestral, englobando o período 2002:01-2011:02. Todos os dados estão em escala logarítmica, com seus componentes cíclicos tendo sido obtidos a partir do filtro Hodrick-Prescott, considerando $\lambda=1.600$. (b) Areas sombreadas correspondem a períodos de recessão na economia brasileira, em consonância com as cronologias desenvolvidas pelo Comitê de Datação dos Ciclos Econômicos (CODACE, 2009) e Gomes e Magalhães (2012).

Fonte: Elaboração própria com base em dados do Sistema Aliceweb/MDIC e PIM-PF/IBGE. 
De acordo com a cronologia proposta pelo CODACE, ocorreram duas recessões durante o período em análise: uma correspondente ao período 2002:04-2003:02 e outra correspondente ao período 2008:03-2009:02. No caso, esta última recessão coincide com a crise financeira de 2007-2008. Por sua vez, no caso da cronologia construída por Gomes e Magalhães (2012), nota-se a ocorrência de um maior número de recessões no período, assim como uma maior amplitude desses episódios quando da comparação com o contexto nacional. Os resultados reportados demonstram que, apesar das três variáveis analisadas exibirem consideráveis oscilações no curto prazo, exportações e importações apresentam uma volatilidade nitidamente superior ao nível de atividade, mensurado a partir do índice de produção industrial do IBGE.

Adicionalmente, vale notar a considerável queda ocorrida nas três variáveis analisadas durante a crise de 2007-2008. Ao longo deste período recessivo, os índices de produção industrial espírito-santense e brasileiro registraram quedas aproximadas de $30 \%$ e 15\%, respectivamente, ao passo que as exportações e importações registraram quedas superiores a 40\% e 20\%. Em termos gerais, ambos os resultados são consistentes com o colapso do comércio exterior reportado na literatura sobre o tema (por exemplo, Levy, 2008; Lopes, 2009; Levchenko, Lewis e Tesar, 2010; Alessandria, Kaboski e Midrigan, 2011).

Por outro lado, no período posterior à crise de 2007-2008, foram registrados padrões de recuperação no nível de atividade e valores exportados e importados. Em particular, ao se analisar a evolução dos componentes cíclicos das séries consideradas, nota-se que, embora a produção industrial tenha alcançado um nível semelhante àquele onde se encontrava no período pré-crise, o mesmo resultado não ocorreu no caso das exportações e importações.

O Gráfico 3 contém a evolução dos componentes cíclicos das séries de produção industrial e saldo da balança comercial do Brasil (gráfico à esquerda) e Espírito Santo (gráfico à direita), ao longo do período 2002:01-2011:02 ${ }^{15}$. Mais uma vez, cada gráfico destaca os períodos recessivos ocorridos para cada unidade analisada.

\footnotetext{
${ }^{15}$ No caso, a variável "saldo comercial" (denotada pela sigla $n x$ ) é definida como a razão entre exportações líquidas e o índice de produção industrial, correspondendo à participação $\mathrm{d}$ sombreadas correspondem a períodos de reces o saldo da balança comercial (exportações menos importações) no produto. Optou-se pela utilização de uma definição nestes moldes para fins de comparação com outros resultados reportados na literatura internacional (por exemplo, Backus, Kehoe e Kydland, 1992, 1994).
} 
Gráfico 3 - Componentes cíclicos do saldo comercial e índice de produção industrial, Brasil e Espírito Santo (2002:01/2011:02)
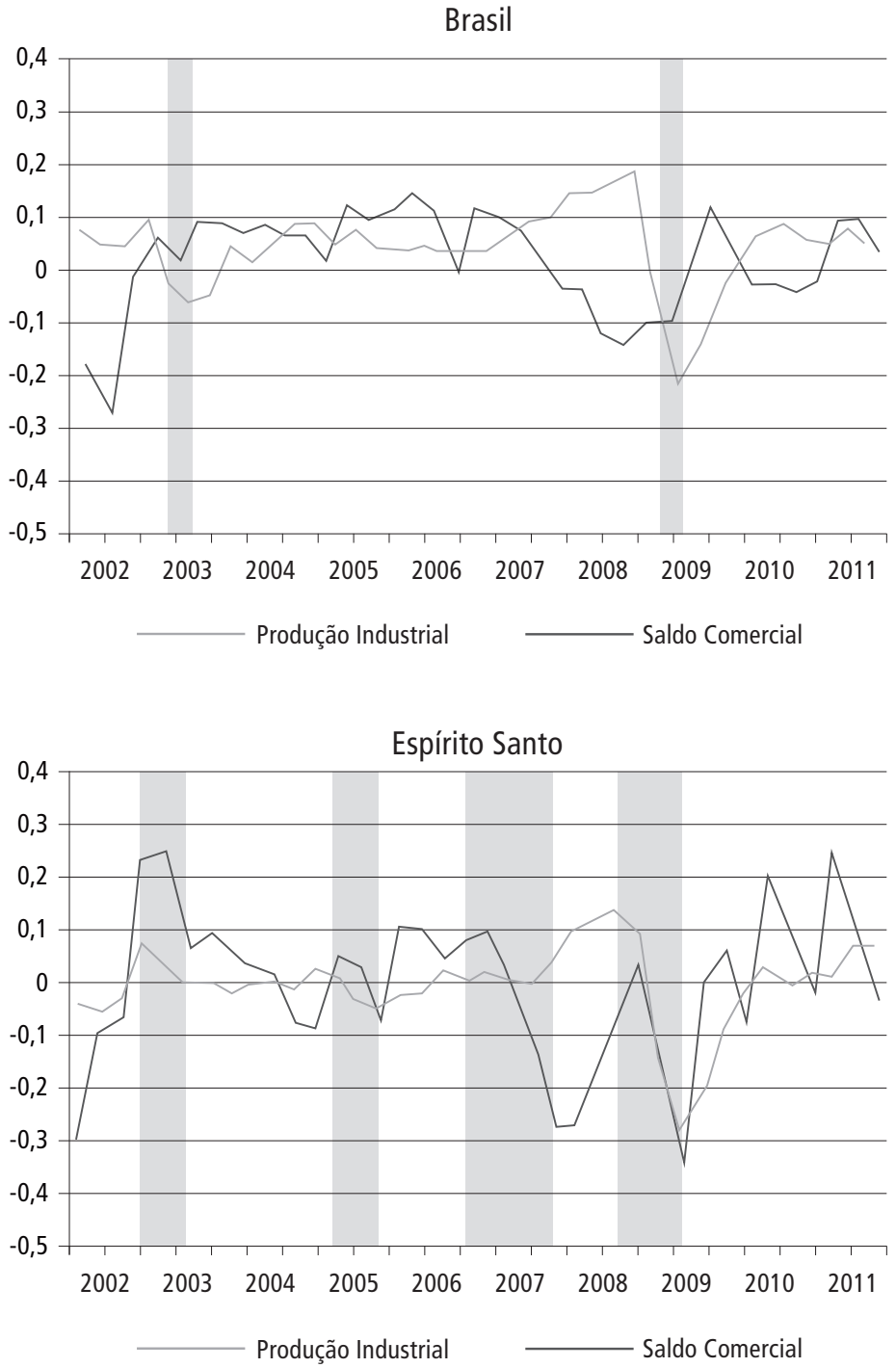

Notas: Os dados utilizados no gráfico possuem periodicidade trimestral, englobando o período 2002:01-2011:02. Todos os dados estão em escala logarítmica, com seus componentes cíclicos tendo sido obtidos a partir do filtro Hodrick-Prescott, considerando $\lambda=1.600$. (b) Áreas sombreadas correspondem a períodos de recessão na economia brasileira, em consonância com as cronologias desenvolvidas pelo Comitê de Datação dos Ciclos Econômicos (CODACE, 2009) e Gomes e Magalhães (2012).

Fonte: Elaboração própria com base em dados do Sistema Aliceweb/MDIC e PIM-PF/IBGE. 
O principal resultado a ser destacado no caso dos gráficos anteriores corresponde à elevada volatilidade do saldo comercial, quando comparado ao nível de atividade. Especificamente, no caso estadual, o desvio-padrão do componente cíclico do saldo comercial é de $23,2 \%$, equivalente a aproximadamente três vezes o desvio-padrão do índice de produção industrial (7,9\%).

Em particular, pode-se notar que, ao longo do período analisado, ambas as variáveis exibiram trajetórias semelhantes, apesar das diferenças em termos de magnitudes das flutuações registradas. No contextonacional, embora também haja certa semelhança em termos de flutuações ocorridas, nota-se que, ao longo de períodos recessivos, as duas variáveis parecem se mover em direções contrárias. Percebe-se, neste último caso, que embora o saldo comercial seja mais volátil que o nível de atividade (desvios-padrão de 21,2\% e 3,6\%, respectivamente), as flutuações cíclicas de ambas as variáveis apresentam menor volatilidade quando da comparação com ocontexto estadual.

A Tabela 5 exibe os momentos de variáveis relacionadas ao comércio exterior ao longo do período 2002:01-2011:02. Na tabela, são reportados valores referentes ao desvio-padrão e coeficientes de correlação cruzada com o produto dos componentes cíclicos das séries para os períodos $t-1, t$ e $t+1$ :

Tabela 5 - Desvio-padrão e coeficientes de correlação, Brasil e Espírito Santo (2002:01-2011:02)

\begin{tabular}{|c|c|c|c|c|c|c|c|c|}
\hline \multirow{3}{*}{ Variáveis } & \multicolumn{4}{|c|}{ Brasil } & \multicolumn{4}{|c|}{ Espírito Santo } \\
\hline & \multirow{2}{*}{$\begin{array}{l}\text { Desvio- } \\
\text { padrão }\end{array}$} & \multicolumn{3}{|c|}{ Correlação Cruzada } & \multirow{2}{*}{$\begin{array}{l}\text { Desvio- } \\
\text { padrão }\end{array}$} & \multicolumn{3}{|c|}{ Correlação Cruzada } \\
\hline & & $t-1$ & $t$ & $t+1$ & & $t-1$ & $t$ & $t+1$ \\
\hline \multirow[t]{2}{*}{ Produção Industrial } & $3,6 \%$ & $0,67^{* * *}$ & $1,00^{* * *}$ & $0,67^{* * *}$ & $7,9 \%$ & $0,70^{* * *}$ & $1,00^{* * *}$ & $0,70^{* * *}$ \\
\hline & & $(0,00)$ & $(0,00)$ & $(0,00)$ & & $(0,00)$ & $(0,00)$ & $(0,00)$ \\
\hline \multirow[t]{2}{*}{ Exportações } & $10,1 \%$ & $0,31^{*}$ & $0,70^{* * *}$ & $0,75^{* * *}$ & $17,6 \%$ & 0,14 & $0,60^{* * *}$ & $0,77^{* * *}$ \\
\hline & & $(0,07)$ & $(0,00)$ & $(0,00)$ & & $(0,41)$ & $(0,00)$ & $(0,00)$ \\
\hline \multirow[t]{2}{*}{ Importações } & $12,5 \%$ & $0,29^{*}$ & $0,74^{* * *}$ & $0,86^{* * *}$ & $17,4 \%$ & 0,05 & $0,40^{* * *}$ & $0,71^{* * *}$ \\
\hline & & $(0,08)$ & $(0,00)$ & $(0,00)$ & & $(0,75)$ & $(0,01)$ & $(0,00)$ \\
\hline \multirow[t]{2}{*}{ Corrente de Comércio } & $10,6 \%$ & $0,32^{*}$ & $0,76^{* * *}$ & $0,84^{* * *}$ & $16,0 \%$ & 0,12 & $0,57^{\star * *}$ & $0,81^{* * *}$ \\
\hline & & $(0,06)$ & $(0,00)$ & $(0,00)$ & & $(0,49)$ & $(0,00)$ & $(0,00)$ \\
\hline \multirow[t]{2}{*}{ Saldo Comercial } & $21,2 \%$ & $-0,32^{* *}$ & $-0,63^{* * *}$ & $-0,62^{* * *}$ & $23,2 \%$ & $-0,27^{*}$ & $-0,30^{*}$ & $-0,32^{\star *}$ \\
\hline & & $(0,04)$ & $(0,00)$ & $(0,00)$ & & $(0,09)$ & $(0,06)$ & $(0,04)$ \\
\hline
\end{tabular}

Notas: (a) Os dados utilizados no gráfico possuem periodicidade trimestral, englobando o período 2002:01-2011:02. Todos os dados estão em escala logarítmica, com seus componentes cíclicos tendo sido obtidos a partir do filtro Hodrick-Prescott, considerando $\lambda=1.600$. (b) A segunda e sexta colunas reportam valores dos desvios-padrão dos componentes cíclicos das séries. (c) As demais colunas da tabela reportam valores de coeficientes de correlação estimados entre os componentes cíclicos das séries, quando tomadas em pares. Os p-valores associados a cada coeficiente estimado são reportados entre parênteses. (d) Os termos $\left({ }^{*}\right),\left(^{* *}\right)$ e $\left.{ }^{* * *}\right)$ denotam significância estatística dos coeficientes estimados aos níveis de $10 \%$, $5 \%$ e $1 \%$, respectivamente.

Fonte: Elaboração própria com base em dados do Sistema Aliceweb/MDIC e PIM-PF/IBGE. 
Os resultados reportados na Tabela 5 permitem constatar que, em termos de volatilidade, todas as variáveis de comércio exterior analisadas apresentam maiores valores, em termos de seus respectivos desvios-padrão, que medidas de nível de atividade. No caso, exportações, importações e corrente de comércio exibem valores de desvio-padrão entre $10 \%$ e 18\%, equivalentes a aproximadamente duasa três vezes o valor do desvio-padrão dos índices de produção industrial considerados, nos moldes descritos originalmente por Engel e Wang (2011), por exemplo. Por sua vez, o saldo da balança comercial apresenta valores significativamente maioresem relação ao desvio-padrão do nível de atividade (entre $21 \%$ e $23 \%$ ).

Qualitativamente, os padrões cíclicos referentes ao setor externo nacional são basicamente os mesmos que no caso do setor externo estadual, embora os valores reportados para a medida de volatilidade empregada sejam menores neste último caso. Um resultado que chama atenção em ambos os casos é o padrão contracíclico do saldo comercial, em consonância com os resultados reportados por Backus, Kehoe e Kydland (1992, 1994). Especificamente, os valores referentes aos coeficientes de correlação estimados demonstram que esta variável tende a ser mais fortemente contracíclica no caso nacional que no caso estadual ${ }^{16}$.

Em termos de grau de associação linear com a medida empregada para representar nível de atividade, os resultados demonstram que todas as variáveis de comércio exterior analisadas apresentam alta conformidade com o ciclo, padrão evidenciado a partir dos valores reportados para os coeficientes de correlação estimados, situados na faixa entre 0,3 e 0,8 (em valores absolutos) e significativos ao nível de $1 \%$, em geral. Adicionalmente, o fato de alguns coeficientes de correlação apresentarem maiores valores no período " $t+1$ " sugere que a grande maioria das variáveis de comércio exterior segue um padrão defasado em relação à produção industrial.

Buscando explorar mais as diferenças de magnitude relacionadas às flutuações cíclicas de variáveis do setor externo nos casos estadual e nacional, a Tabela 6 apresenta uma comparação quantitativa entre Espírito Santo e Brasil, em termos de volatilidade. A segunda coluna da tabela apresenta os desvios-padrão das variáveis de comércio exterior do Brasil, ao passo que a terceira coluna apresenta a mesma estatística para o Espírito Santo. A quarta coluna, por sua vez, apresenta a razão entre os valores das

\footnotetext{
16 Pinheiro (2005, p. 17) reporta um resultado qualitativamente semelhante a partir da utilização de dados agregados. O autor reporta um coeficiente de correlação contemporânea entre saldo comercial e nível de atividade (medido a partir do PIB) de - 0,45 para o Brasil. Por outro lado, de acordo com seus resultados, o saldo comercial apresenta uma menor volatilidade relativa em comparação à medida agregada de nível de atividade empregada em sua análise (1,43\% contra 3,68\%), respectivamente.
} 
colunas anteriores. As linhas finais desta tabela apresentam ainda valores da média e mediana referentes a cada unidade analisada. O intuito básico dos resultados reportados é ressaltar eventuais diferenças, em termos de volatilidade, entre as economias nacional e estadual. Os resultados são descritos a seguir.

Tabela 6 - Volatilidade de variáveis de comércio exterior, Brasil e Espírito Santo (2002:01-2011:02)

\begin{tabular}{l|c|c|c}
\hline \multicolumn{1}{c|}{ Variável } & Brasil (1) & Espírito Santo (2) & Magnitude Relativa (2)/(1) \\
\hline Produção Industrial & 3,60 & 7,90 & 2,19 \\
\hline Exportações & 10,10 & 17,60 & 1,74 \\
\hline Importações & 12,50 & 17,40 & 1,39 \\
\hline Corrente de Comércio & 10,60 & 16,00 & 1,51 \\
\hline Saldo Comercial & 21,19 & 23,26 & 1,09 \\
\hline Média & 11,60 & 16,43 & 1,59 \\
\hline Mediana & 10,60 & 17,40 & 1,51 \\
\hline
\end{tabular}

Notas: (a) Os dados utilizados no gráfico possuem periodicidade trimestral, englobando o período 2002:01-2011:02. Todos os dados estão em escala logarítmica, com seus componentes cíclicos tendo sido obtidos a partir do filtro Hodrick-Prescott, considerando $\lambda=1.600$. (b) A segunda coluna da tabela reporta valores de desvio-padrão para os componentes cíclicos de variáveis de comércio exterior do Brasil, enquanto que a terceira coluna reporta valores de desvio-padrão para os componentes cíclicos de variáveis de comércio exterior do estado do Espírito Santo. A quarta coluna reporta a razão entre os valores da terceira e segunda colunas, respectivamente.

Fonte: Elaboração própria com base em dados do Sistema Aliceweb/MDIC e PIM-PF/IBGE.

A comparação de resultados referentes a medidas de volatilidade de variáveis de comércio exterior do Espírito Santo e Brasil revela que, em geral, as flutuações cíclicas tendem a ser mais pronunciadas no estado que no país, fato evidenciado pelos resultados referentes à média e mediana da magnitude relativa das flutuações (valores de 1,6 e 1,5, respectivamente). Em particular, pode-se notar que todas as variáveis analisadas apresentam maiores valores de desvio-padrão no caso estadual que no caso nacional, o que ressalta a maior volatilidade relativa do setor externo espírito-santense.

Em suma, os resultados reportados na Tabela 6 demonstram que, no caso das variáveis analisadas, o estado do Espírito Santo apresenta, em média, flutuações mais voláteis que o Brasil. A princípio, um resultado nestes moldes está de acordo com a evidência disponível relacionada às flutuações cíclicas ocorridas no estado desde a década de 1990 (Magalhães e Ribeiro, 2011; Gomes e Magalhães, 2012), assim como às características de seu comércio exterior (Pereira e Maciel, 2010; Magalhães e Toscano, 2012a, 2012b, 2012d).

Uma vez que o comportamento do saldo comercial constitui um dos mais importantes resultados apresentados originalmente por Backus, Kehoe e Kydland (1994), a Tabela 7 apresenta estatísticas enfatizando o comportamento cíclico desta variável. 
Especificamente, são reportados na tabela valores de coeficientes de correlação relacionando as variáveis saldo comercial $(n x)$, nível de atividade $(y)$ e termos de troca $(p)$, tomadas em pares $^{17}$.

Tabela 7 - Coeficientes de correlação cruzada: saldo comercial $(n x)$, termos de troca (p) e nível de atividade (y), Brasil e Espírito Santo (2002:01-2011:02)

\begin{tabular}{l|c|c|c}
\hline & Corr(nx, y) & Corr(nx, p) & Corr $(\mathbf{y}, \mathbf{p})$ \\
\hline \multirow{2}{*}{ Brasil } & $-0,63^{* * *}$ & $0,34^{* *}$ & $-0,54^{* * *}$ \\
& $(0,00)$ & $(0,03)$ & $(0,00)$ \\
\hline \multirow{2}{*}{ Espírito Santo } & $-0,30^{*}$ & $-0,35^{* *}$ & $-0,15$ \\
& $(0,06)$ & $(0,03)$ & $(0,38)$ \\
\hline
\end{tabular}

Notas: (a) Os dados utilizados no gráfico possuem periodicidade trimestral, englobando o período 2002:01-2011:02. Todos os dados estão em escala logarítmica, com seus componentes cíclicos tendo sido obtidos a partir do filtro Hodrick-Prescott, considerando $\lambda=1.600$. (b) A segunda coluna da tabela reporta valores de coeficientes de correlação entre componentes cíclicos de medidas de saldo comercial $(n x)$ e nível de atividade $(y)$. A terceira coluna reporta valores de coeficientes de correlação entre componentes cíclicos de medidas de saldo comercial $(n x)$ e termos de troca $(p)$. A quarta coluna reporta valores de coeficientes de correlação entre componentes cíclicos de medidas de nível de atividade $(y)$ e termos de troca $(p)$. (c) P-valores das estatísticas são reportados entre parênteses. (d) Os termos $\left.\left({ }^{*}\right),{ }^{* *}\right)$ e $\left.{ }^{* * *}\right)$ denotam significância estatística dos coeficientes estimados aos níveis de $10 \%, 5 \%$ e $1 \%$, respectivamente.

Fonte: Elaboração própria com base em dados do Sistema Aliceweb/MDIC e PIM-PF/IBGE.

Os resultados reportados permitem algumas inferências acerca dos padrões cíclicos envolvendo as variáveis consideradas. Em primeiro lugar, nota-se que, conforme enfatizado anteriormente, tanto no caso do estado quanto do país, o saldo comercial apresenta um padrão contracíclico (coeficientes de correlação de -0,30 e -0,63, respectivamente).

Em segundo lugar, quando da análise dos coeficientes estimados relacionando saldo comercial e termos de troca, os resultados obtidos são destoantes: ao passo que o estado apresenta um valor negativo para este coeficiente $(-0,35)$, o país apresenta um resultado positivo $(0,34)$. Ainda que ambos os coeficientes sejam estatisticamente significativos, apenas o primeiro está de acordo com a evidência reportada em Backus, Kehoe e Kydland (1994, p. 87).

Em terceiro lugar, os coeficientes estimados entre nível de atividade e termos de troca apresentam valores negativos, embora apenas o coeficiente referente ao caso nacional

17 Vale a ressalva de que a definição de $p$ ("termos de troca") utilizada no presente trabalho difere daquela geralmente empregada em análises aplicadas. Especificamente, esta variável foi construída como a razão entre preços de importações e exportações. Apesar desta definição corresponder ao inverso daquela utilizada em outros estudos (por exemplo, Moura e Da Silva, 2005), ela corresponde à definição convencional em estudos de macroeconomia aberta (Backus, Kehoe e Kydland, 1994, p. 85). 
seja estatisticamente significativo $(-0,54)$. Basicamente, este último resultado aponta para um padrão contracíclico dos termos de troca no caso brasileiro ${ }^{18}$.

Um resultado adicional, a ser verificado no presente contexto, equivale ao padrão gráfico dos coeficientes de correlação cruzada entre saldo comercial $(n x)$ e termos de troca $(p)$, buscando-se averiguar a eventual ocorrência de uma "curva-S", nos moldes propostos por Backus, Kehoe e Kydland (1994). O Gráfico 4 reporta os resultados deste experimento.

\section{Gráfico 4 - Coeficientes de correlação cruzada, Espírito Santo e Brasil (2002:01-2011:02)}

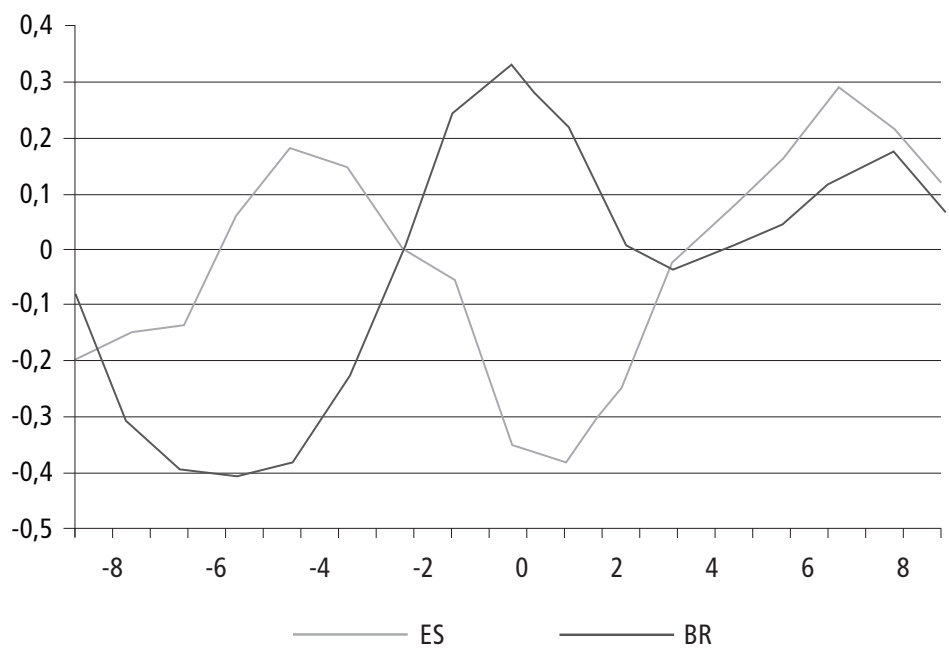

Nota: Dados trimestrais. Os dados utilizados no gráfico correspondem a coeficientes de correlação cruzada entre as variáveis saldo comercial $(n x)$ e termos de troca $(p)$.

Fonte: Elaboração própria com base em dados do Sistema Aliceweb/MDIC e PIM-PF/IBGE.

Mais uma vez, a comparação direta dos padrões gráficos reportados aponta para nítidas diferenças entre país e estado. Embora o Brasil apresente, à primeira vista, um padrão qualitativamente similar àquele descrito por Backus, Kehoe e Kydland (1994) para distintos países (“curva-S”), o mesmo não parece ocorrer no caso estadual. Em

${ }^{18}$ Considerando uma amostra de 11 países, Backus, Kehoe e Kydland (1994) obtêm resultados onde as correlações estimadas entre saldo comercial e nível de atividade $(\operatorname{Corr}(n x, y))$ assumem valores negativos em todos os casos, embora sejam estatisticamente significativas no caso de seis países. Por sua vez, as correlações estimadas entre nível de atividade e termos de troca $(\operatorname{Corr}(y, p))$ assumem valores negativos no caso de cinco países, embora sejam estatisticamente significativas apenas para um país. Finalmente, as correlações estimadas entre saldo comercial e termos de troca $(\operatorname{Corr}(n x, p))$ assumem valores negativos no caso de oito países, sendo estatisticamente significativas para seis países (Backus, Kehoe e Kydland 1994, p. 87). 
particular, a análise da evolução dos coeficientes de correlação cruzada entre balança comercial e termos de troca demonstra que o Espírito Santo segue um padrão nitidamente distinto do Brasil, com ampla variação nos valores reportados. Por outro lado, apesar do país apresentar um padrão gráfico consistente com a curva-S, vale ressaltar que as correlações estimadas não são, em geral, estatisticamente significativas ${ }^{19}$.

\section{CONCLUSÕES E AGENDA DE PESQUISA FUTURA}

O presente trabalhou buscou documentar as principais regularidades empíricas (fatos estilizados) referentes ao padrão cíclico de variáveis de comércio exterior no estado do Espírito Santo e Brasil, atentando para eventuais diferenças existentes entre estas unidades de análise. Os principais resultados obtidos a partir deste esforço de pesquisa foram os seguintes:

i) Em termos de volatilidade, variáveis relacionadas ao comércio exterior são nitidamente mais voláteis que medidas de nível de atividade. Em particular, exportações e importações apresentaram desvios-padrão correspondentes a duas ou três vezes o desvio-padrão do índice de produção industrial, tanto no caso estadual quanto no caso nacional;

ii) Com relação a direções de movimento, todas as variáveis de comércio exterior apresentam um padrão procíclico e defasado, em média, com magnitudes de coeficientes de correlação entre 0,70 e 0,80 ;

iii) A variável saldo comercial apresenta um padrão marcadamente contracíclico (coeficientes de correlação entre -0,60 e -0,30), resultado em consonância com a literatura internacional relacionada ao tema;

iv) As flutuações de variáveis de comércio são, em média, mais voláteis no caso do estado do Espírito Santo que no caso do Brasil (1,6 vezes);

v) No tocante à correlação cruzada entre saldo comercial e termos de troca, não são obtidas evidências favoráveis a um resultado nos moldes de uma "curva-S”, seja no caso estadual ou nacional.

19 A título de informação, vale ressaltar que foram realizados testes de robustez relacionados aos principais resultados reportados nesta seção. Basicamente, estes testes concentraram-se na estimação de medidas de volatilidade e correlação cruzada a partir da utilização de métodos alternativos de estacionarização das séries de comércio exterior estadual e nacional, como o filtro Band-Pass (Baxter e King, 1999; Christiano e Fitzgerald, 2003), por exemplo. Em termos gerais, os resultados obtidos (não reportados) foram qualitativamente robustos a alterações desta natureza. 
Os resultados reportados são importantes principalmente por constituírem evidência inicial relacionada à ocorrência de ciclos de negócios em variáveis de comércio exterior nos contextos nacional e estadual. Em particular, a documentação das principais regularidades empíricas relacionadas às flutuações cíclicas em economias abertas pode constituir um importante passo em direção à construção e simulação de ambientes macroeconômicos artificiais, assim como fornecer ingredientes necessários à formulação e implementação de políticas voltadas para o setor externo.

Em termos de pesquisa futura, são feitas três sugestões. Primeiro, seria interessante realizar um estudo em moldes semelhantes a este, voltado para a dinâmica de comércio exterior em todos os estados brasileiros. Embora tenham ocorrido esforços anteriores nessa direção (por exemplo, Souza, 2003), uma meta desejável seria verificar a possível ocorrência de regularidades e anomalias em frequências cíclicas para as demais UF, buscando-se, ao mesmo tempo, compreender as razões subjacentes aos resultados eventualmente obtidos.

Segundo, o desenvolvimento de modelos teóricos, em moldes semelhantes àqueles propostos por Mendoza (1991), Backus, Kehoe e Kydland (1992, 1994) e Engel e Wang (2011) poderia ser útil no sentido de fornecer insights adicionais acerca do funcionamento de pequenas economias abertas e da importância do comércio exterior em cada uma delas, tanto no caso estadual quanto nacional.

Finalmente, fica a sugestão de realização de estudos relacionados a bases de dados longitudinais, contendo informações detalhadas em nível de firmas individuais. Em particular, análises voltadas para o comportamento de firmas exportadoras, que enfatizem o papel desempenhado por processos de abertura comercial, nos moldes dos estudos sumarizados por Melitz (2008), por exemplo, poderiam fornecer relevantes informações acerca da importância do comércio internacional no curto prazo ${ }^{20}$.

\section{REFERÊNCIAS BIBLIOGRÁFICAS}

ALESSANDRIA, G.; KABOSKI, J.P.; MIDRIGAN, V. U.S. trade and inventory dynamics. American Economic Review (Papers and Proceedings), v. 101, n. 2, p. 303-307, mai. 2011.

AMBLER, S.; CARDIA, E.; ZIMMERMANN, C. International business cycles: what are the facts? Journal of Monetary Economics, v. 51, n. 2, p. 257-276. mar. 2004.

\footnotetext{
${ }^{20}$ Ver, a este respeito, Bartelsman e Doms (2000), Bonelli (2006) e Kannebley (2011). Para um exemplo de aplicação empírica relacionada ao tema, ver Arkolakis e Muendler (2010).
} 
ARKOLAKIS, C.; MUENDLER, M. A. The extensive margin of exporting goods: a firm-level analysis. NBER Working Paper, n. 16.641, dez. 2010.

BACKUS, D. K.; KEHOE, P. J. International evidence on the historical properties of business cycles. American Economic Review, v. 82, n. 4, p. 864-888, 1992.

BACKUS, D. K.; KEHOE, P. J.; KYDLAND, F. International real business cycles. Journal of Political Economy, v. 100, n. 4, p. 745-775, ago. 1992.

BACKUS, D.K.; KEHOE, P.J.; KYDLAND, F. Dynamics of the trade balance and the terms of trade: the J-curve? American Economic Review, v. 84, n. 1, p. 84-103, mar. 1994.

BARTELSMAN, E. J.; DOMS, M. Understanding productivity: lessons from longitudinal microdata. Journal of Economic Literature, v. 38, n. 3, p. 569-594, set. 2000.

BASU, S.; TAYLOR, A. M. Business cycles in international historical perspective. Journal of Economic Perspectives, v. 13, n. 2, p. 45-68, 1999.

BAXTER, M.; KING, R. G. Measuring business cycles: approximate band-pass filters for economic time series. Review of Economics and Statistics, v. 81, n. 4, p. 575-593, nov. 1999.

BLANCHARD, O. J. What do we know about macroeconomics that Fisher and Wicksell did not? Quarterly Journal of Macroeconomics, v. 115, n. 4, p. 1375-1411, nov. 2000.

BLANCHARD, O.J. The crisis: basic mechanisms, and appropriate policies. IMF Working Paper, n. 09/80, abr. 2009.

BONELLI, R. "O desempenho exportador das firmas industriais brasileiras e o contexto macroeconômico". In: DE NEGRI, J. A.; ARAÚJO, B. C. P. O. (Orgs.) As empresas brasileiras e o comércio internacional. Brasília: IPEA, 2006, p. 271-315.

BRESSER-PEREIRA, L. C. Crise e recuperação da confiança. Revista de Economia Política, v. 29, n. 1, p. 133-134, jan./mar. 2009.

BRUNNERMEIER, M. K. Deciphering the liquidity and credit crunch of 2007-08. Journal of Economic Perspectives, v. 23, n. 1, p. 77-100, 2009.

CHARI, V. V. Nobel laureate Robert E. Lucas, Jr.: architect of modern macroeconomics. Journal of Economic Perspectives, v. 12, n. 1, p. 171-186, 1998.

CHRISTIANO, L. J.; FITZGERALD, T. J. The Band Pass Filter. International Economic Review, v. 44, n. 2, p. 435-465, mai. 2003.

COMITÊ DE DATAÇÃO DE CICLOS ECONÔMICOS (CODACE). Criação do CODACE. Rio de Janeiro: IBRE-FGV, mai. 2009.

COOLEY, T. F.; PRESCOTT, E. C. Economic growth and business cycles. In: COOLEY, T. F. (Ed.) Frontiers of business cycle research. New Jersey: Princeton University, 1995, p. 1-38.

CUNHA, A.; MOREIRA, L. P. Ciclos econômicos regionais no Brasil de 1985 a 2002: uma introdução. Revista de Economia Contemporânea, v. 10, n. 1, p. 115-138, jan./mar. 2006.

DANTHINE, J. P.; DONALDSON, J. B. Methodological and empirical issues in real business cycle theory. European Economic Review, v. 37, n. 1, p. 1-35, 1993. 
DE PAULA, L. F. "Preferência pela liquidez e a natureza da 'crise' brasileira”. In: FERRARI FILHO, F.; DE PAULA, L. F. (Eds.) Dossiê da crise. Porto Alegre: Associação Keynesiana Brasileira, Programa de Pós-Graduação em Economia da Universidade Federal do Rio Grande do Sul, 2008, p. 64-68.

ELLERY, R. G. Jr.; GOMES, V. Ciclo de negócios no Brasil durante o século XX: uma comparação com a evidência internacional. Economia, v. 6, n. 1, p. 45-66, jan./jul. 2005.

ELLERY, R. G. Jr.; GOMES, V.; SACHSIDA, A. Business cycle fluctuations in Brazil. Revista Brasileira de Economia, v. 56, n. 2, p. 269-308, abr./jun. 2002.

ENGEL, C.; WANG, J. International trade in durable goods: understanding volatility, cyclicality and elasticities. Journal of International Economics, v. 83, n. 1, p. 37-52, jan. 2011.

FERREIRA, P. C. G.; VAL, P. R. C. Modelos de ciclos reais de negócios aplicados à economia brasileira. Pesquisa e Planejamento Econômico, v. 31, n. 2, p. 213-248, ago. 2001.

GOMES, F. A. R.; MAGALHÃES, M. A. Construindo uma cronologia mensal de recessões para o estado do Espírito Santo. In: Encontro de Economia do Espírito Santo III EEES, 3, Vitória, ES, out. 2012.

GOPINATH, G.; ITSHOKI, O.; NEIMAN, B. Trade prices and the global trade collapse of 20082009. NBER Working Paper, n. 17594, nov. 2011.

HIDALGO, A. B.; FEISTEL, P. R. Mudanças na estrutura do comércio exterior brasileiro: uma análise sob a ótica da teoria de Hecksher-Ohlin. Estudos Econômicos, v. 43, n. 1, p. 79-108, jan./mar. 2013.

HODRICK, R.; PRESCOTT, E. C. Post-War U.S. business cycles: a descriptive empirical investigation. Journal of Money, Credit and Banking, v. 29, n. 1, p. 1-16, 1997.

KANCZUK, F.; FARIA, F., Jr. Ciclos reais para a indústria brasileira? Estudos Econômicos, v. 47, n. 4, p. 335-350, 2000.

KANNEBLEY, S., Jr. Firmas heterogêneas e exportações: uma resenha à luz das evidências brasileiras. Revista de Economia Contemporânea, v. 15, n. 1, p. 143-170, jan./abr. 2011.

KING, R. G.; REBELO, S. "Ressuscitating real business cycles”. In: TAYLOR, J.; WOODFORD, M. (Eds.) Handbook of Macroeconomics. North-Holland: Elsevier, 2000, p. 927-1007.

KUME, H.; PIANI, G.; MIRANDA, P. "Política comercial, instituições e crescimento econômico no Brasil". In: KUME, H. (Org.) Crecimiento económico, instituciones, política comercial y defensa de La competência em el Mercosur. Montevidéu: Red Mercosur, v. 11, p. 97-155, 2008.

KYDLAND, F.; PRESCOTT, E. C. Business cycles: real facts and a monetary myth. Federal Reserve Bank of Minneapolis Quarterly Review, v. 14, n. 2, p. 3-18, 1990.

LEIBOVICI, F.; WAUGH, M. E. On cyclical fluctuations in international trade volumes. New York: New York University, mar. 2011, mimeo.

LEVCHENKO, A. A.; LEWIS, L. T.; TESAR, L. L. The collapse of international trade during the 2008-2009 crisis: in search of the smoking gun. IMF Economic Review, v. 58, n. 2, p. $214-$ 253, dez. 2010. 
LEVY, P. M. O Brasil e a crise financeira internacional. Revista Brasileira de Comércio Exterior, n. 97 , p. 6-11, out./dez. 2008.

LOPES, F. L. "A dimensão da crise". In: BACHA, E. L.; GOLDFAJN, I. (Orgs.) Como reagir à crise? Políticas econômicas para o Brasil. Rio de Janeiro: Imago, 2009, p. 13-16.

LUCAS, R. E., Jr. "Understanding business cycles”. In: BRUNNER, K.; MELTZER, A. (Eds.) Stabilization of the domestic and international economy. Amsterdam: North-Holland Publishing Company, 1977, p. 7-29.

LUCAS, R. E., Jr. Methods and problems in business cycle theory. Journal of Money, Credit and Banking, v. 12, n. 4, p. 696-715, 1980.

MAGALHÃES, M. A. Explicando os ciclos de negócios. Revista de Economia Aplicada, v. 4, n. 1, p. 157-189, jan./mar. 2000.

MAGALHÃES, M. A. Equilíbrio e ciclos. Revista de Economia Contemporânea, v. 9, n. 3, p. 509554, set./dez. 2005.

MAGALHÃES, M. A. Preços de commodities e nível de atividade em uma pequena economia aberta: evidências empíricas para o estado do Espírito Santo. Economia e Sociedade, v. 20, n. 3, p. 533-566, dez. 2011.

MAGALHÃES, M. A.; RIBEIRO, A. P. L. Fatos estilizados dos ciclos de negócios no estado do Espírito Santo: uma abordagem quantitativa. Revista Econômica do Nordeste, v. 42, n. 3, p. 597-620, jul./set. 2011.

MAGALHÃES, M. A.; TOSCANO, V. N. Grau de abertura da economia do estado do Espírito Santo no período $1^{\circ}$ trim./04 - 2 trim./09. Indicadores Econômicos FEE, v. 37, n. 4, p. 225 240, 2010.

MAGALHÃES, M. A.; TOSCANO, V. N. “Abertura, concentração e volatilidade: uma análise do comércio exterior do Espírito Santo ao longo do período 1996-2010”. In: MAGALHÃES, M. A.; TOSCANO, V. N. (Orgs.) A Economia do Espírito Santo: novas visões. Vitória: CORECONES, 2012a, p. 1-20.

MAGALHÃES, M. A.; TOSCANO, V. N. Distribuições em cauda longa e comércio internacional: uma investigação empírica de padrões de concentração na pauta de exportações do Espírito Santo, em 1996-2010. Ensaios FEE, v. 33, n. 2, p. 571-602, nov. 2012b.

MAGALHÃES, M. A.; TOSCANO, V. N. Fatos do comércio exterior no Espírito Santo. Vitória: Instituto Jones dos Santos Neves, 2012c, mimeo.

MAGALHÃES, M. A.; TOSCANO, V. N. Há diferenças entre as pautas de exportação e importação do estado do Espírito Santo? Economia \& Tecnologia, v. 8, n. 3, p. 85-94, jul./set. 2012d.

MCCALLUM, B. T. "Real business cycle models". In: BARRO, R. (Ed.) Handbook of modern business cycle theory. Oxford: Basil Blackwell, 1989, p. 16-50.

MELITZ, M. J. "International trade and heterogeneous firms". In: DURLAUF, S. N.; BLUME, L. E. (Eds.) The New Palgrave Dictionary of Economics. 2 ed. London: McMillan, 2008.

MENDOZA, E. G. Real business cycles in a small open economy. American Economic Review, v. 81, n. 4, p. 797-818, set. 1991. 
MOURA, G.; DA SILVA, S. Is there a Brazilian J-Curve? Economics Bulletin, v. 6, n. 10, p. 1-17, 2005.

PEREIRA, L. V.; MACIEL, D. S. “O comércio exterior do estado do Espírito Santo”. In: VESCOVI, A. P. V.; BONELLI, R. (Orgs.) Espírito Santo: instituições, desenvolvimento e inclusão social. Vitória: IJSN, 2010, p. 95-137.

PINHEIRO, F. O. D. Modelos de ciclos reais de negócios em pequena economia aberta aplicados ao Brasil. Dissertação de Mestrado, Programa de Pós-Graduação em Economia, Fundação Getúlio Vargas, Rio de Janeiro, 2005.

PLOSSER, C. I. Understanding real business cycles. Journal of Economic Perspectives, v. 3, n. 3, p. 51-77, 1989.

PRATES, A. M. Q. O setor exportador do Espírito Santo nos anos recentes: estrutura, vantagens comparativas e comércio intra-industrial. In. Encontro de Economia do Espírito Santo, 1, Vitória, ES, 2010.

PRATES, D. M. A alta recente dos preços das commodities. Revista de Economia Política, v. 27, n. 3, p. 323-344, 2007.

PRATES, D. M.; MARÇAL, E. F. O papel do ciclo de preços no desempenho recente das exportações brasileiras. Análise Econômica, v. 49, p. 163-191, mar. 2008.

RIBEIRO, F. J. Uma breve avaliação dos primeiros impactos da crise internacional sobre os fluxos de comércio exterior do Brasil. Revista Brasileira de Comércio Exterior, n. 99, p. 20-39, abr./ jun. 2009.

SOUZA, N. J. Abertura comercial e crescimento dos estados brasileiros, 1991-2000. Teoria e Evidência Econômica, v. 11, n. 21, p. 41-61, nov. 2003.

STADLER, G. W. Real business cycles. Journal of Economic Literature, v. 32, n. 4, p. 1.750-1.783, dez. 1994.

STOCK, J. H.; WATSON, M. "W. Business cycle fluctuations in U.S. macroeconomic time series". In: TAYLOR, J.; WOODFORD, M. (Eds.) Handbook of Macroeconomics. London NorthHolland, 2000, p. 3-64.

WOODFORD, M. Revolution and evolution in twentieth-century macroeconomics. Princeton University, jun. 1999, mimeo.

ZARNOWITZ, V. Recent work on business cycles in historical perspective: a review of theories and evidence. Journal of Economic Literature, v. 23, n. 2, p. 523-580, 1985. 